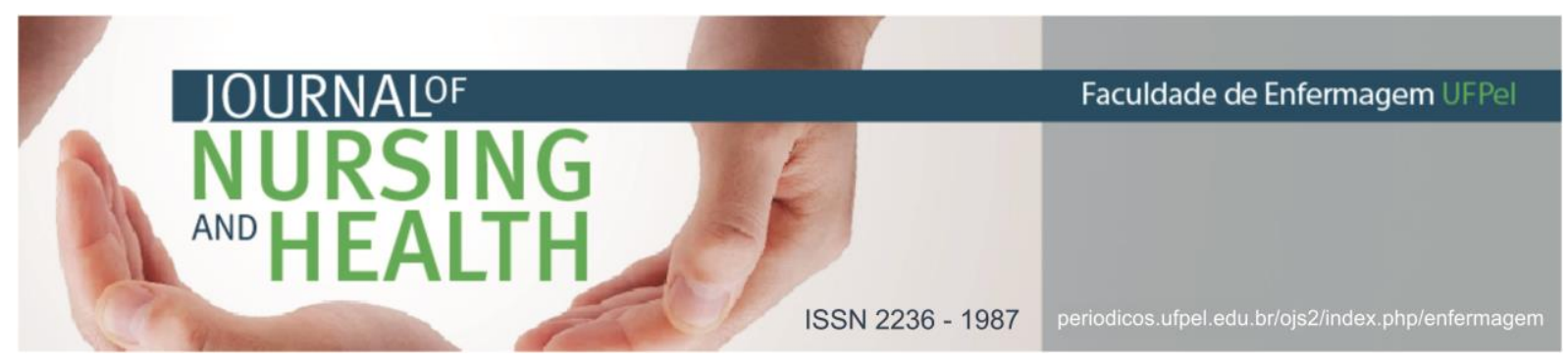

ARTIGO ORIGINAL

\title{
Rede de apoio familiar à gravidez e ao parto na adolescência: uma abordagem moscoviciana
}

\author{
Family support network for pregnancy and childbirth in adolescence: a Moscovian \\ approach
}

\section{Red de apoyo familiar al embarazo y al parto en la adolescencia: una abordaba moscoviciana}

Matos, Greice Carvalho de ${ }^{1}$; Soares, Marilu Correa²; Escobal, Ana Paula de Lima ${ }^{3}$; Quadro, Pricilla Porto ${ }^{4}$; Rodrigues, Juliana Baptista ${ }^{5}$

Como citar este artigo: Matos GC, Soares MR, Escobal APL, Quadro PP, Rodrigues JB. Rede de apoio familiar à gravidez e ao parto na adolescencia: uma abordagem moscoviciana. J. nurs. health. 2019;9(1):e199106

\section{RESUMO}

Objetivo: identificar as redes de apoio familiar às mulheres que vivenciaram a gestação e o parto recorrentes na adolescência. Métodos: estudo descritivo com abordagem qualitativa. Fizeram parte desta pesquisa 30 mulheres que vivenciaram a gestação e o parto recorrente na adolescência. Os dados foram coletados por meio de entrevista semiestruturada e analisados com base na Análise Textual Discursiva. Resultados: a família apresentou-se como principal fonte de apoio, a presença da mesma foi atrelada a discursos positivos, confirmando o pressuposto inicial deste estudo, de que a fragilidade na rede de apoio desencadeia, na adolescente, sentimentos negativos do processo de gestar e parir. Considerações finais: a figura materna apresentou-se como principal rede de apoio sendo referenciada como importante suporte para a adolescente na vivência da gestação e do parto. Descritores: Adolescente; Gravidez na adolescência; Apoio social.

\section{ABSTRACT}

Objective: to identify family support networks for women who experienced recurrent gestation and childbirth during adolescence. Methods: descriptive study with a qualitative approach. Thirty women who experienced gestation and recurrent birth during adolescence were part of this study. Data were collected through a semi-structured interview and analyzed based on the Discursive Textual Analysis. Results: the family was the main source of support, its presence was linked to positive discourses, confirming the initial assumption of this study, that the fragility in the support

1 Enfermeira. Mestre em Enfermagem. Universidade Federal de Pelotas (UFPEL). E-mail: greicematos1709@hotmail.com http://orcid.org/0000-0003-4479-4896

2 Enfermeira. Doutora em Saúde Pública. Universidade Federal de Pelotas (UFPEL). E-mail: enfmari@uol.com.br http://orcid.org/0000-0001-9171-1083

3 Enfermeira. Doutora em Ciências. Universidade Federal de Pelotas (UFPEL). E-mail: anapaulaescobal@hotmail.com http://orcid.org/0000-0002-2601-9098

4 Discente do curso de Enfermagem. Universidade Federal de Pelotas (UFPEL). E-mail: pricillaporto@hotmail.com http: / / orcid.org/0000-0003-1363-9199

5 Enfermeira. Universidade Federal de Pelotas (UFPEL). E-mail: rodrigues.b_juliana@yahoo.com.br http://orcid.org/0000-0002-0432-0584 


\section{JOURNALOF

network triggers, in the adolescent, negative feelings of the process of gestating and to give birth. Final considerations: the maternal figure was referred as the main support network for the adolescent in the experience of gestation and childbirth.

Descriptors: Adolescent; Pregnancy in adolescence; Social support.

\section{RESUMEN}

Objetivo: identificar las redes de apoyo familiar a las mujeres que vivenciaron la gestación y el parto recurrentes en la adolescencia. Métodos: estudio descriptivo con enfoque cualitativo. Hicieron parte de esta investigación 30 mujeres que vivenciaron la gestación y el parto recurrente en la adolescencia. Los datos fueron recolectados por medio de una entrevista semiestructurada y analizados con base en el análisis textual discursivo. Resultados: la familia se presentó como principal fuente de apoyo, la presencia de la misma fue ligada a discursos positivos, confirmando el presupuesto inicial de este estudio, de que la fragilidad en la red de apoyo desencadena, en la adolescente, sentimientos negativos del proceso de gestar y parir. Consideraciones finales: la figura materna se presentó como principal red de apoyo siendo referenciada como importante soporte para la adolescente en la vivencia de la gestación y del parto.

Descriptores: Adolescente; Embarazo en adolescencia; Apoyo social.

\section{INTRODUÇÃO}

A adolescência é definida como período da vida humana repleto de alterações no âmbito físico, cognitivo e social, sendo a transição da infância para a vida adulta. 0 processo de gestar e parir na adolescência representa um fator adicional com o qual a adolescente precisa lidar.1 Porém, quando possui uma rede de apoio familiar este pode contar com proteção frente às situações de vulnerabilidade, potencializando condições melhores de vida e o enfrentamento do período de forma mais plena e saudável. ${ }^{2}$

A rede de apoio surge como suporte à adolescente no que se refere ao enfrentamento dos desafios decorrentes das transformações físicas, mentais e sociais, contribuindo no seu desenvolvimento pessoal e social e na sua autonomia frente às escolhas e decisões. Esta rede pode ser familiar, de educadores, profissionais de saúde e grupos de iguais integrados em projetos sociais e educativos. ${ }^{3-4}$
Além disso, a adolescente grávida pode ter sua rede de apoio modificada em relação às pessoas que a compõem e os papéis que exercem, as mulheres que não á possuem tendem ao isolamento e a diminuição de contatos com amigos, não encontrando pessoas com quem compartilhar suas angustias, medos e questionamentos que permeiam o processo de gestar $\mathrm{e}$ parir. ${ }^{5}$

Nesta conjuntura foi realizado um estudo que buscou avaliar a percepção sobre apoio social de adolescentes que vivenciam a maternidade. Os resultados do mesmo apontaram para as genitoras como figura central do apoio familiar às adolescentes, sendo as mesmas figuras centrais no contexto familiar, mantendo relações íntimas e significativas com as mesmas. ${ }^{2}$

Ainda, nesta perspectiva um estudo avaliou as percepções de adolescentes sobre seu processo de gestação, neste a figura materna também surgiu como ponto central na 


\section{NURSING \\ AND \\ HEALTH}

comunicação da gravidez, as adolescentes apresentaram como justificativa a escolha materna, por acreditarem que esta é mais compreensiva que a figura paterna. ${ }^{6}$ Em outro estudo também é evidente tais apontamentos, cujo a figura paterna foi relatada pelas adolescentes como a que mais teve problemas em aceitar tanto a gestação como a chegada da criança. ${ }^{7}$

Estudos apontam para vivências negativas do processo de gestar e parir quando se tem a rede de apoio familiar fragilizada, neste contexto adolescentes mães ficam expostas às situações de vulnerabilidade e exclusão social. Há relatos de mães que as expulsaram de casa e a induziram ao aborto, pais que deixaram de falar e a não aceitação da gravidez por parte do companheiro. ${ }^{8-9}$

Neste contexto no que se refere aos serviços de saúde, sabe-se que muitas vezes, as adolescentes sentemse julgadas pelos profissionais de saúde, por esta razão e pelas situaçõos de vulnerabilidade que estão sujeitas acabam não frequentando as consultas de pré-natal, bem como não seguem as orientações fornecidas.

É evidente a necessidade dos profissionais de saúde redefinirem sua postura em relação à mãe adolescente e sua rede de apoio. 0 grande desafio é o estabelecimento de vínculo com a adolescente e inclusão da família que também sofre influência das modificações advindas da gravidez e reconhecer seu importante papel, manter um canal de confiança para um relacionamento terapêutico que auxilie não só no cuidado a criança,
ISSN 2236 - 1987

como também na formação de sua identidade, enquanto mulher. ${ }^{10}$

A partir destas reflexões construiu-se este estudo com 0 objetivo de identificar as redes de apoio familiar às mulheres na vivência de gestações e partos recorrentes na adolescência.

\section{MATERIAIS E MÉTODOS}

Pesquisa qualitativa descritiva, fundamentada na Teoria das Representações Sociais proposta por Serge Moscovici. ${ }^{11}$ Foi realizada em seis Unidades Básicas de Saúde (UBS), de uma cidade do sul do Estado do Rio Grande do Sul. Fizeram parte deste estudo trinta mulheres adultas que vivenciaram a gestação e o parto recorrente na adolescência. A escolha por entrevistar mulheres, e não adolescentes, justificou-se por acreditar que o tempo é primordial para a realização de reflexões acerca dos fatos vivenciados, e com a maturidade, a mulher pode expressar de maneira mais concreta as representações sociais acerca do parto recorrente.

O procedimento para coleta de dados ocorreu por meio da técnica Snowball (bola de neve), método de amostragem intencional que permite a definição de uma amostra por meio das indicações procedidas por pessoas que compartilham ou conhecem outras com características em comum de interesse do estudo. ${ }^{12}$

Os dados foram coletados no período entre maio e agosto de 2015, por meio de entrevista semiestruturada gravada, a partir de perguntas disparadoras envolvendo as 


\section{JOURNALOF \\ NURSING \\ ANO HEALTH}

ISSN 2236 - 1987

temáticas: gravidez na adolescência, vivência do parto e da recorrência, formação do conhecimento sobre o processo de gestação e parturição e redes de apoio.

A análise dos dados foi feita sob a luz da Análise Textual Discursiva (ATD) buscando-se sustentação no referencial teórico da Teoria das Representações Sociais (TRS), na vertente moscoviciana. ${ }^{13}$

A pesquisa desenvolveu-se em conformidade com a Resolução 466/2012 do Conselho Nacional de Saúde. ${ }^{14} 0$ projeto foi aprovado pelo Comitê de Ética em Pesquisa da Faculdade de EnfermagemUniversidade Federal de Pelotas, parecer $\mathrm{n}^{0} 1.066 .085$ e Certificado de Apresentação para Apreciação Ética (CAAE) 43861015.7.0000.5317. 0 Termo de Consentimento Livre e Esclarecido (TCLE) foi assinado por todas as participantes da pesquisa e o anonimato foi assegurado por meio da utilização da inicial " $M$ " referindo-se a mulher acrescida da idade atual e ordem numérica da entrevista. Exemplo: M.25.1; M.23.2.

\section{RESULTADOS E DISCUSSÃO}

Quanto à caracterização das mulheres apresentadas observa-se que a faixa etária variou de 20 a 61 anos; quanto ao número de gestações variouse entre duas e 10 gestações; 22 respondentes afirmaram que apresentavam com companheiro até o momento da entrevista. Quanto ao nível de escolaridade, uma era analfabeta, 22 tinham ensino fundamental incompleto, três cursaram o ensino fundamental completo, uma possuía ensino médio incompleto, duas com ensino médio completo e uma com ensino superior incompleto. Das participantes do estudo apenas seis referenciaram estarem inseridas no mercado de trabalho. No que refere a renda familiar 15 mulheres relataram um salário mínimo (o salário mínimo considerado na entrevista foi de RS $788,00)$, sete recebiam menos que um salário mínimo e oito informaram renda superior à um salário mínimo.

O apoio social na adolescência auxilia na assistência das necessidades sociais e emocionais dos indivíduos, contribuindo para o fortalecimento de recursos individuais e no enfrentamento das adversidades próprias da idade. Essas estratégias são fundamentais para a promoção da saúde, incentivando comportamentos saudáveis. ${ }^{3}$

Ao considerar que a gravidez na adolescência, mesmo quando planejada, pode desencadear uma sobreposição de crises surge a necessidade da consolidação de uma rede de apoio social no decorrer deste processo como atenuantes de sentimentos estressores para a adolescente vivenciar 0 período gestacional de maneira tranquila e prazerosa.

Quando as participantes foram questionadas quanto ao apoio recebido durante 0 processo de parturição, observou-se que a presença da figura materna foi considerada de extrema importância para que a vivência desse momento fosse definida como positiva.

O bom é que minha mãe ficou comigo todo o tempo, $e$ isso me acalmava [...] então eu considero 
que foi ótimo ela estar lá comigo. (M.25.12)

Foi minha mãe que ficou comigo, ter ela ao meu lado nesse momento foi muito bom, saber que alguém que tu confia está ali do teu lado, te olhando, te cuidando, te passando uma tranquilidade, até porque este momento querendo ou não nos deixa muito nervosa. (M.22.2)

Sabe-se que vivenciar o processo de gestação e parturição na adolescência traz consigo uma gama de sentimentos negativos e/ou positivos, a adolescente busca constantemente aceitação no meio social no qual está inserida. Assim percebe-se que a figura materna emerge como "porto seguro" permitindo a adolescente vivenciar o processo de gestar e parir com tranquilidade.

Este fato corrobora com os resultados de um estudo que objetivou conhecer as experiências e percepções de 10 mães cujas filhas engravidaram durante a adolescência, a relação mãefilha durante a gestação foi relatada como normal e boa pela maioria das mães. Muitas delas afirmaram dar apoio por meio de diálogo e acompanhando-as durante a nova fase, o relacionamento entre ambas mudou para melhor após o nascimento do bebê. A presença da mãe pode favorecer sentimentos de maior segurança à adolescente, bem como maior confiança e adaptação à maternidade, a figura materna surge como eixo para a continuação dos projetos de vida, bem como o fortalecimento dos vínculos familiares. ${ }^{7}$
Também, nos discursos das participantes do presente estudo que o companheiro também surgiu como apoio.

Acho que meu marido sempre ir comigo me ajudou, porque ele mandava eu ficar calma, e respirar fundo, ele dizia que não entendia muito o que estava acontecendo, mas que eu me acalmasse[...]. (M.23.8)

0 papel do companheiro como parte da rede de apoio, participante ativo do processo de parturição, emerge como figura de extrema importância para boa evolução do trabalho de parto.

A boa aceitação da gravidez e apoio recebido por parte do companheiro é relevante na redução da sobrecarga emocional da adolescente, amplia a adesão cuidado pré-natal e contribui para a vivência da maternidade de forma prazerosa. ${ }^{5}$

Evidenciou-se na fala das participantes a presença da rede de apoio constituída por outros familiares. No discurso de M.28.6, que aponta a sogra como pessoa de confiança.

Minha sogra, minha mãe e meu marido, mas na hora do parto só quem estava lá era minha sogra, acho que foi bom ela estar comigo sim, pois era uma pessoa da minha confiança. (M.28.6)

O discurso M.28.6 corrobora com resultados de um estudo que apresenta outros membros da família como apoio necessário e constante para a adolescente grávida, no qual citam à avó, à tia e a sogra, que fazem um 


\section{JOURNALOF \\ NURSING \\ M०HEALTH}

movimento de mobilização e aproximação com a chegada do novo membro da família, motivando sentimentos de calma e confiança. ${ }^{10}$ No presente estudo, outras pessoas foram apontadas pelas participantes como fonte de apoio.

Meu pai e minha mãe sempre estiveram presentes no parto $e$ sempre na minha vida, hoje moro e trabalho com eles, ai sabe como é, empresa da família sempre dá brigas, problemas que trazemos para casa, mas no fim dá tudo certo e a gente se dá bem. (M.20.19)

Eu e minha irmã tivemos que virar gente grande bem cedo, mas uma ajuda a outra no que pode, $e$ vamos seguindo a vida. (M.24.25)

Os discursos de M.20.19 e M.24.25 demonstram que independente do membro da família, quando a adolescente compreende que ao seu redor tem uma rede de apoio, relata sua vivência de maneira positiva, enfatizando o quanto o amparo e a companhia são de extrema relevância neste momento de suas vidas.

A gravidez prematura pode trazer o desamparo social como abandono da família e do companheiro, no qual a gravidez, para algumas adolescentes, não foi reconhecida como positiva em suas vidas, mas como sinônimo de rejeição. ${ }^{8}$

Eu lá sozinha como sempre, e isso é difícil, tu não ter apoio de ninguém, alguém para se firmar, te ajudar, te apoiar, minha mãe até foi um dia me visitar dessa segunda vez, mas não ficou lá, porque era véspera de ano novo. (M.41.7)

No hospital eu me senti mais insegura, porque mesmo sabendo de como ia ser eu preferia que minha mãe tivesse lá comigo quando eu estava sentindo as dores. (M.21.27)

Eles descobriram minha gravidez e também me colocaram para fora de casa, aí fiquei morando na casa dos vizinhos, aí depois que a guria nasceu eu tive que dar ela porque não tinha como ficar cuidando. (M.32.23)

Meu primeiro parto foi um pouco triste porque minha mãe não estava por perto, como tínhamos brigado quando sai de casa, a gente voltou a se falar só depois que consegui me livrar do meu ex-marido, aí fui para o hospital sozinha quando senti as dores do parto. (M.40.16)

Os referidos discursos caracterizam que a fragilidade na rede de apoio familiar resulta em representações de gestar e parir embasadas na solidão, na insegurança e no medo de vivenciar o processo. Sendo assim, a fragilidade da rede de apoio estaria ligada às representações negativas que a gravidez na adolescência representa na sociedade. Seria o motivo da dificuldade no enfrentamento da família em lidar com a situação? Ou estaria ligada à desestrutura das famílias das participantes?

Enfatiza-se que a maneira como a adolescente percebe o apoio ao seu redor resulta na maneira como a 
mesma vai lidar com suas adversidades. Se a percepção é de preconceito social com a gravidez na adolescência, esta adolescente reage com afastamento e autoexclusão do grupo social (possível verificar no discurso de M.40.16). Por se sentir envergonhada e insegura, a jovem, muitas vezes se isola do meio social, dos amigos, devido a atritos familiares e incertezas quanto ao futuro. ${ }^{5,15}$

Desta forma, enfatiza-se a necessidade de fomentar junto à comunidade, os familiares, os profissionais e os educadores sobre a importância de redes de apoio às adolescentes com gravidez e parto recorrente, tensionando que esta população vivencie a gravidez precoce de forma positiva e com objetivo de empoderá-las não somente para a vivência do processo de parturição, como também, fortalecê-las para o exercício de sua condição de cidadã ativa na sociedade.

\section{CONSIDERAÇÕES FINAIS}

0 presente estudo permitiu identificar as redes de apoio familiares das mulheres na vivência das gestações e partos recorrentes na adolescência.

No que se refere ao apoio recebido na vivência do parto, a família apresentou-se como principal fonte de apoio, a presença da mesma foi atrelada a discursos positivos, confirmando o pressuposto inicial deste estudo, de que a fragilidade na rede de apoio desencadeia, na adolescente, sentimentos negativos do processo de gestar e parir.

Neste sentido, é importante que os profissionais de saúde e familiares, acolham esta adolescente grávida despindo-se de julgamentos e preconceitos, tencionando a adesão ao pré-natal, no sentido de vivenciar a gestação e um parto tranquilo, surgindo neste contexto uma mulher que pode sim dedicar-se aos estudos e ao mercado de trabalho, para tanto a rede de apoio é primordial.

A limitação encontrada para o desenvolvimento do referido estudo, foi a dificuldade de acesso às participantes, pois em muitas vezes os nomes fornecidos pelos serviços de saúde de referência não coincidiam com o endereço indicado, o que desencadeou atraso na coleta de dados.

Recomenda-se que novos estudos sejam realizados, aprofundando as representações sociais do processo de parturição na vertente de profissionais de saúde, bem como familiares de mulheres que foram mães na adolescência, pois entende-se que ambos são a fonte primária para a reconstrução, recriação e reapresentação de representações sociais do processo de parturição na adolescência.

\section{REFERÊNCIAS}

1 Rosseto MS, Schermann LB, Beria JU. Maternidade na adolescência: indicadores emocionais negativos $\mathrm{e}$ fatores associados em mães de 14 a 16 anos em Porto Alegre, RS, Brasil. Ciênc. Saúde Colet. [Internet]. 2014[acesso em 2018 dez 19];19(10):4235-46. Disponível em: http://www.scielo.br/scielo.php?scrip $\mathrm{t}=\mathrm{sci}$ arttext\&pid=S1413-

$81232014001004235 \& \operatorname{lng}=e n \& n r m=$ iso \&tlng=pt 


\section{ISSN 2236 - 1987}

2 Braga IF, Oliveira WA, Spanó AM, Nunes MR, Silva MAI. Percepções de adolescentes sobre o apoio social na maternidade no contexto da atenção primária. Esc. Anna Nery Rev. Enferm. [Internet]. 2014[acesso em $2018 \mathrm{dez}$ 19];18(3):448-55. Disponível em: http://www.scielo.br/scielo.php?scrip $\mathrm{t}=\mathrm{sci} \_$arttext\&pid=S1414.

$81452014000300448 \& \operatorname{lng}=e n \& n r m=i s o$ \&ttlng=pt

3 Costa RF, Zeitoune RCG, Queiroz MVO, Gómez García Cl, Ruiz García MJ. Redes de apoio ao adolescente no contexto do cuidado à saúde: interface entre saúde, família e educação. Rev. Esc. Enferm. USP. [Internet]. 2015[acesso em 2018 dez 19];49(5):741-47. Disponível em: http://www.revistas.usp.br/reeusp/a rticle/view/106686/105304

4 Munslinger IM, Silva SM, Bortoli CFC, Guimarães KB. A maternidade na perspectiva de mães adolescentes. Rev. bras. promoç. saúde (Impr.). [Internet]. 2016[acesso em $2018 \mathrm{dez}$ 19];29(3):357-63. Disponível em: http://periodicos.unifor.br/RBPS/arti cle/view/4541/pdf

5 Pio DAM, Capel MS. Os significados do cuidado na gestação. Revista psicologia e saúde [Internet]. 2015[disponível em 2018 dez 19];7(1):74-81. Disponível em: http://pepsic.bvsalud.org/scielo.php? script=sci_arttext\&pid=S2177093X2015000100010

6 Santos NLB, Guimaraes DA, Gama CAP. A percepção de mães adolescentes sobre seu processo de gravidez. Revista psicologia e saúde [Internet]. 2016[acesso em $2018 \mathrm{dez}$ 19];8(2):83-96. Disponível em: http://pepsic.bvsalud.org/scielo.php? script=sci_arttext\&pid=S2177093X2016000200007\&lng=pt\&nrm=iso\& tlng=pt

7 Fernandes AO, Santos JHPO, Gualda DMR. Gravidez na adolescência: percepções das mães de gestantes jovens. Acta Paul. Enferm. (Online). [Internet]. 2012[acesso em $2018 \mathrm{dez}$ 19];25(1):55-60. Disponível em: http://www.scielo.br/scielo.php?scrip $\mathrm{t}=\mathrm{sci}$ arttext\&pid=S0103-

21002012000100010

8 Rodrigues ARS, Barros WM, Soares PDFL. Reincidência da gravidez na adolescência: percepções das adolescentes. Enferm. foco (Brasília). [Internet]. 2016[acesso em $2018 \mathrm{dez}$ 19];7(3/4):66-70. Disponível em: http://revista.cofen.gov.br/index.php /enfermagem/article/view/945/355

9 Matos GC de, Escobal APL, Palma JS, Gonçalves KD, Blank EB, Soares MC. Parto normal ou cesárea na adolescência: de quem é a decisão? Rev. enferm. UFPE on line. [Internet]. 2018[acesso em 2018 dez 19];12(6):1681-7. Disponível em: https://periodicos.ufpe.br/revistas/r evistaenfermagem/article/download/ $231069 / 29211+\& c d=1 \& h l=p t-$

BR\&ct $=c \operatorname{lnk} \& g l=b r$

10 Cremonese L, Wilhelm LA, Prates LA, Paula CC, Sehnem GD, Ressel LB. Apoio social na perspectiva da puérpera adolescente. Esc. Anna Nery Rev. Enferm. [Internet]. 2017[acesso em 2018 dez 19];21(4):1-8. Disponível em:

http://www.scielo.br/pdf/ean/v21n4 /pt_1414-8145-ean-2177-9465-EAN2017-0088.pdf 


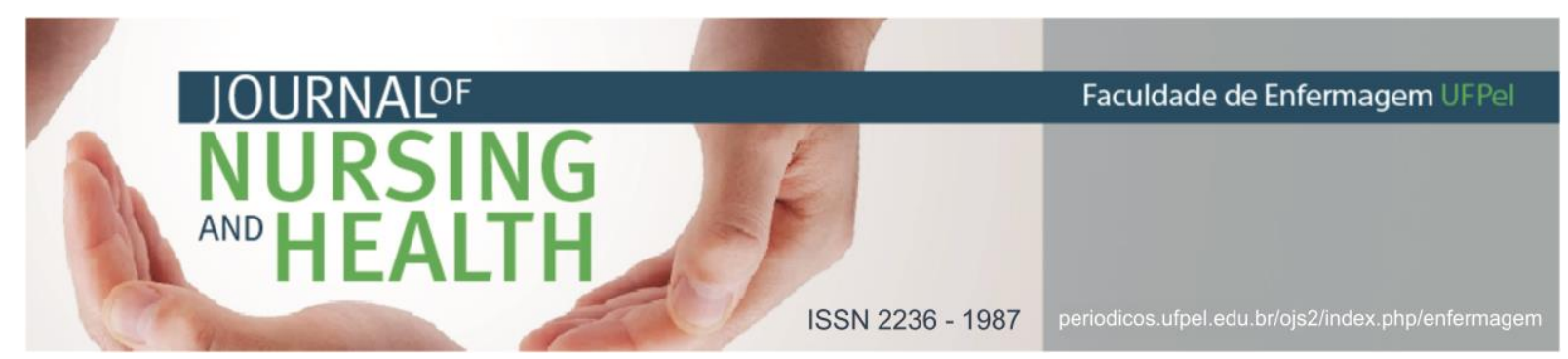

11 Goodman LA. Snowball Sampling. Annals of Mathematical Statistics. Isecet siam. 1999;32(1):148-70.

12 Moraes R, Galiazzi MC. Análise textual discursiva. $2^{a}$ ed. Ijuí: $E d$. Unijuí; 2011.

13 Ministério da Saúde (BR). Conselho Nacional de Saúde. Resolução 466, de 12 de dezembro de 2012: diretrizes e normas regulamentadoras de pesquisa envolvendo seres humanos. Brasília; 2012.

14 Oliveira LFM, Davim RMB, Alves ESRC, Rodrigues ESRC, Nóbrega MF, Torquato JA. Vivência de puérperas adolescentes quanto à gravidez e trabalho de parto. Rev. enferm. UFPE on line. [Internet]. 2016 jan/mar[acesso em 2015 set 12];10(2):395-406. Disponível em: pesquisa.bvsalud.org/portal/resource /pt/bde-28257

15 Góes TRV, Correia DS. Estresse e lócus de controle em adolescentes grávidas. Revista portal saúde e sociedade [Internet]. 2016[acesso em 2018 dez 19];1(1):5-17. Disponível em: www.seer.ufal.br/index.php/nuspfam ed/article/download/2371/2190+\&cd $=2 \& \mathrm{hl}=\mathrm{pt}-\mathrm{BR} \& \mathrm{ct}=\mathrm{clnk \& gl}=\mathrm{br}$

Data de submissão: 13/12/2017

Data de aceite: 18/11/2018

Data de publicação: 08/01/2019 